\title{
Lucia Omacini, Le Roman épistolaire français au tournant des Lumières
}

\section{Regina Bochenek-Franczakowa}

\section{(2) OpenEdition}

10 Journals

\section{Édition électronique}

URL : http://journals.openedition.org/studifrancesi/36107

DOI : 10.4000/studifrancesi.36107

ISSN : 2421-5856

Éditeur

Rosenberg \& Sellier

\section{Édition imprimée}

Date de publication : 1 juillet 2005

Pagination : 160-161

ISSN : 0039-2944

\section{Référence électronique}

Regina Bochenek-Franczakowa, « Lucia Omacini, Le Roman épistolaire français au tournant des

Lumières », Studi Francesi [En ligne], 145 (XLIX | I) | 2005, mis en ligne le 30 novembre 2015, consulté le

19 avril 2021. URL : http://journals.openedition.org/studifrancesi/36107 ; DOI : https://doi.org/

10.4000/studifrancesi.36107

Ce document a été généré automatiquement le 19 avril 2021.

\section{(c)}

Studi Francesi è distribuita con Licenza Creative Commons Attribuzione - Non commerciale - Non opere derivate 4.0 Internazionale. 


\title{
Lucia Omacini, Le Roman épistolaire français au tournant des Lumières
}

\author{
Regina Bochenek-Franczakowa
}

\section{RÉFÉRENCE}

LUCIA OMACINI, Le Roman épistolaire français au tournant des Lumières, Paris, Honoré Champion, 2003, («Les Dix-huitième siècles», 82), pp. 279.

1 L'histoire du roman épistolaire français semble déjà bien connue, et pourtant, il en reste encore beaucoup de zones mal explorées, voire ignorées, ce que Lucia Omacini vient de prouver dans son dernier ouvrage. L'A. se propose d'y vérifier l'hypothèse selon laquelle le roman épistolaire déclinait rapidement à la $\mathrm{fm}$ du XVIII ${ }^{\mathrm{e}}$ siècle pour disparaître au XIX ${ }^{\mathrm{e}}$, ce qu'elle fait sur un corpus de textes embrassant la période de 1790 à 1830. Renonçant à une présentation chronologique ou thématique, elle garde celle fondée sur des catégories narratives. Ainsi l'ouvrage est-il construit autour de quatre groupes de problèmes: le statut du roman épistolaire, le «style de l'événement», la description topographique et le savoir fragmentaire. La notion-clé de l'analyse est «la dérive» qui manifeste l'état d'épuisement du genre à l'époque. Mais l'A. veut en dégager le «revers positif» lié à la pratique de l'écriture fragmentaire: trait qui, paradoxalement, montre le genre qu'on croit éteint et épuisé au seuil du romantisme, se parer des séductions du roman contestataire, touchant aux limites de l'anti-roman. Comme l'A. l'a bien démontré, cela ne concerne que les chefs-d'œuvre de la période examinée car la production «moyenne» se satisfaisait des recettes rassurantes, ce qui, malheureusement, n'a fait que renforcer le processus de la sclérose du genre. Il s'avère que c'est du côté du récit de l'événement et de celui de la description topographique qu'est venu l'éclatement de la formule narrative épistolaire «canonique».

2 Le roman par lettres à voix multiples, tel qu'il était pratiqué au $18^{\mathrm{e}}$ siècle, s'est montré impuissant devant l'événement révolutionnaire: l'A parle d'«incompatibilité» entre ce dernier et le récit épistolaire, tant au niveau structural qu'idéologique. Mais si l'examen 
du corpus des textes révèle la prépondérance des romans par lettres qui occultent l'événement révolutionnaire ou s'en distancient par un dépaysement spatial et/ou temporel, il est certain, remarque l'A., que tous les romans épistolaires, surtout les sentimentaux, portent les traces indélibiles d'une souffrance qui est suscitée par le drame de la Révolution. L'A. souligne que le roman par lettres du tournant des Lumières est écartelé entre deux pôles extrêmes: celui de 1'«atrophie narrative» d'Oberman et celui de «la pléthore formelle» de Sade, ce qui est la conséquence à la fois de la nature composite du roman par lettres et de l'impact de la réalité des bouleversements révolutionnaires. L'A. remarque cependant un phénomène intéressant: la formule épistolaire sous le Consulat et l'Empire est utilisée pour des fins idéologiques, conformistes, mais encore commerciales: en fait, le roman par lettres devient un «roman de consommation».

La description topographique est l'autre facteur qui accélère la disparition du roman par lettres classique. La description de la nature, de préférence expressive, impliquant le sujet et son point de vue, devient une composante de plus en plus marquante du genre; dans le brassage des formules narratives, jointe au journal de voyage, elle va contribuer à infléchir le roman par lettres vers la monodie épistolaire. Enfin, le savoir fragmentaire, quoique inhérent au genre, est ici renforcé par le mélange de discours et de formes divers. L'A. a voulu montrer que le roman par lettres, dans sa forme canonique fondée sur l'échange et le désir de communiquer, n'a pas pu survivre à la société des Lumières, mais que, sous le choc de la Révolution, sous l'influence aussi du changement des mentalités, des goûts et des esthétiques, il devient une formule narrative revenant «aux sources du moi». Il devient aussi, aux yeux de l'A., synonyme de la modernité littéraire «et peut-être le point de rupture d'une transformation sans retour» (p. 203). On ne saurait rendre compte ici de la richesse d'aperçus de L. Omacini qui, de plus, a effectué un travail de pionnier. L'ouvrage avec la bibliographie des romans examinés ainsi que les biogrammes des auteurs (en grande partie inconnus) comble une lacune cuisante dans la connaissance du roman épistolaire français $d u$ tournant des Lumières. 